\title{
AS NOÇÕES DE PAISAGEM: UMA ABORDAGEM MULTIDISCIPLINAR PARA O DIAGNÓSTICO AMBIENTAL E A GESTÃO TERRITORIAL
}

\section{Landscape Notions: a Multidisciplinary Approach to Environmental Diagnosis and Territorial Management}

\author{
Mariza Ferreira da Silva \\ Doutoranda do Programa de Pós-graduação em Geografia Universidade Federal do Paraná \\ marizzafs@hotmail.com
}

\begin{abstract}
RESUMO: Este artigo é resultado de pesquisa bibliográfica sobre as variadas noções de paisagem, a partir de uma abordagem multidisciplinar. A psicologia e a fenomenologia da percepção, a arquitetura e a arte, a ecologia e geoecologia ofereceram aportes conceituais e metodológicos para o entendimento da paisagem na perspectiva do diagnóstico ambiental e da gestão territorial. A síntese da contribuição epistemológica de alguns autores, por meio da revisão bibliográfica, permitiu compreender os significados da paisagem em diferentes matrizes paradigmáticas. Diante da constatada multiplicidade conceitual e da revalorização da paisagem como objeto de estudo, bem como da complexidade atual, o trabalho de investigação explorou uma possibilidade de abordagem contemporânea, capaz de subsidiar o planejamento e o ordenamento territorial. Do ponto de vista teórico, os recursos analíticos demonstraram ser relevantes para investigar a diferenciação paisagística. Do ponto de vista metodológico, os SIGs - Sistemas de Informações Geográficas foram considerados, pois são ferramentas relevantes para a análise integrada das varáveis da paisagem.
\end{abstract}

Palavras-chave: Percepção; Fenomenologia; História Geográfica da Paisagem; Geoecologia; Ordenamento Territorial.

ABSTRACT: This article is the result of a bibliographical research on the varied notions of landscape, from a multidisciplinary approach. Psychology and the phenomenology of perception, architecture and art, ecology and geoecology offered conceptual and methodological contributions to the understanding of the landscape in the perspective of environmental diagnosis and territorial management. The synthesis of the epistemological contribution of some authors, through the bibliographical revision, allowed understanding the meanings of the landscape in different paradigmatic matrices. Considering the multiplicity conceptual and the revaluation of the landscape as an object of study, as well as the current complexity, the research work explored a possibility of a contemporary approach capable of subsidizing planning and territorial planning. From the theoretical point of view, the analytical resources proved to be relevant to investigate landscape differentiation. From the methodological point of view, the GIS - Geographic Information Systems were considered, since they are relevant tools for the integrated analysis of landscape variables.

Keywords: Perception; Phenomenology; Geographic History of Landscape; Geoecology; Land use planning

\section{INTRODUÇÃO}

Este artigo, de abordagem multidisciplinar, é o resultado de pesquisa teórica, pesquisas bibliográficas e reflexões teórico-metodológicas. Tem como objetivos: apresentar a síntese da discussão crítica da noção de paisagem, em suas variadas concepções e em diferentes matrizes, do ponto de vista histórico-geográfico; refletir sobre as influências da fenomenologia da percepção na concepção contemporânea 
AS NOÇÕES DE PAISAGEM: UMA ABORDAGEM MULTIDISCIPLINAR PARA O DIAGNÓSTICO AMBIENTAL E A GESTÃO TERRITORIAL

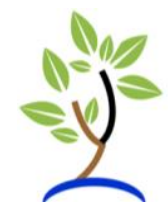

de paisagem; discutir criticamente os métodos para o diagnóstico de paisagens no planejamento e gestão territorial.

A problemática está relacionada à variedade de bases conceituais para entender as noções de paisagem, em diversos campos analíticos e em diversas visões paradigmáticas. Percebe-se essa variação, tanto do ponto de vista histórico quanto do ponto de vista geográfico, cujo entendimento de seus significados, está vinculado ao contexto sociocultural e político.

Do ponto de vista semântico, o vocábulo que expressa o significado de paisagem é polissêmico. Há várias acepções para uma só palavra. Sua concepção é, portanto, holística, cujo conceito é multidisciplinar e determinado pelo movimento da sociedade, que está em constante mudança.

$\mathrm{Na}$ análise de Schier (2003) tradicionalmente, os geógrafos distinguem paisagem natural de paisagem cultural. A paisagem natural "refere-se aos elementos combinados de terreno, vegetação, solo, rios e lagos". Paisagem cultural, humanizada, "inclui todas as modificações feitas pelo homem, como nos espaços urbanos e rurais". De modo geral, segundo ele, "o estudo da paisagem exige um enfoque, do qual se pretende fazer uma avaliação definindo o conjunto dos elementos envolvidos, a escala a ser considerada e a temporalidade na paisagem". Ou seja, "trata-se da apresentação do objeto em seu contexto geográfico e histórico, levando em conta a configuração social e os processos naturais e humanos" (SCHIER, 2003, p.80).

De acordo com Maximiano (2004) a paisagem pode ser entendida como "produto das interações entre elementos de origem natural e humana, em um determinado espaço" e "organizam-se de maneira dinâmica, ao longo do tempo e do espaço", resultando daí, como explicou "feições e condições também dinâmicas, diferenciadas ou repetidas, o que permite uma classificação, ao agruparem-se os arranjos similares, separando-os dos diferentes". Ou seja, "no todo, forma-se um mosaico articulado", sendo que "este processo poderá ser tão detalhado ou amplo, quanto interesse ao observador" (MAXIMIANO, 2004, p. 90).

Apesar da noção de paisagem evoluir-se para uma categoria científica e ter sido historicamente originária da Geografia, a tendência atual para o estudo da paisagem, é buscar a articulação entre as diversas acepções, valorizando-a como patrimônio natural e cultural. Mateo Rodriguez (2005) relacionou, em seus estudos, o conceito de cultura, identidade e paisagem como elementos de coesão dentro das sociedades:

\begin{abstract}
A paisagem é a fisionomia, a morfologia ou a expressão formal do espaço e dos territórios e reflete a visão que a população tem de seu entorno. A paisagem tem como função suportar uma identidade, e servir de base para estimular a coesão realizada dentro da sociedade e rejeitar a influência dos (des) articuladores externos. A paisagem é assim, o fundamento da formação das identidades. A paisagem integra a linguagem científica com a emocional, permitindo o reforçamento mútuo entre o saber geográfico e a identidade cultural (MATEO RODRIGUEZ, 2005, p.1 - Tradução Minha) ${ }^{1}$.
\end{abstract}

\footnotetext{
${ }^{1}$ No original lê-se: "El paisaje es la fisionomía, la morfología o la expresión formal del espacio y de los territórios y refleja la visión que la población tiene sobre su entorno. El paisaje tiene como función soportar una identidad, y servir de base para estimular la cohesión hacia adentro de las sociedades, y
}

REVISTA GEONORTE, V.9, N.33, p.16-36, 2018.

DOI: 10.21170/geonorte.2018.V.9.N.33.16.36

(ISSN 2237 - 1419) 
AS NOÇÕES DE PAISAGEM: UMA ABORDAGEM MULTIDISCIPLINAR PARA O DIAGNÓSTICO AMBIENTAL E A GESTÃO TERRITORIAL

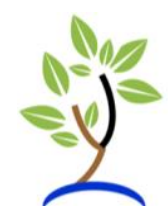

A paisagem considerada por Mateo Rodriguez (2005) é "um grupo de formas, dos objetos e elementos relacionais que definem um espaço geográfico, pois é dentro de seus limites que ocorrem as inter-relações sociais, econômicas e culturais com o meio natural e com as transformações experienciadas". Esse tipo de interpretação, na evolução do processo capitalista, toma como referência "a delimitação política de um território, no processo de acumulação de riqueza e na globalização da natureza". Entende-se, ainda que as edificações humanas, "elementos concretos arquiteturais transformaram a paisagem natural em uma determinada época e projetaram a valorização econômica do espaço - riqueza material e imaterial, acoplada a esses elementos arquitetônicos".

$\mathrm{Na}$ definição de paisagem, na contemporaneidade, incorpora-se uma relação de componentes imbricados e "uma influência política que impregna os aspectos econômicos, locais e mundiais, na era da globalização da natureza e natureza da globalização". Como analisou Porto-Gonçalves (2012, p. 20):

\begin{abstract}
A superação do desafio ambiental inscrito no cerne da globalização neoliberal requer a compreensão das questões colocadas pelo movimento da contracultura daqueles anos de 1960 na medida em que o período de globalização neoliberal que a partir dali se desenvolve se faz exatamente contra aquele movimento. Ver o processo de globalização por essa ótica é importante para entender o complexo e contraditório processo histórico em que se inscreve o desafio ambiental e, assim, encontrar alternativas a ele (PORTO-GONÇALVES, 2012, p. 20).
\end{abstract}

Para Claval (2002), a paisagem "não se apresenta tão-somente como um reflexo do funcionamento passado ou presente da sociedade. As relações emocionais entre a paisagem e o observador são analisadas", pois "o papel da paisagem nas estratégias de poder e de dominação é explorado. A significação da paisagem na construção ou na preservação das paisagens das identidades é ressaltada" (CLAVAL, 2002, p. 21; 26).

Do ponto de vista ecológico, Mateo Rodriguez, Silva e Cavalcante (2007, p.13) apresentaram densa reflexão na obra "Geoecologia das paisagens: uma visão geossistêmica da análise ambiental". Segundo eles, a Geoecologia da Paisagem reveste-se de fundamental importância no âmbito de uma nova perspectiva, "onde as ideias da multidisciplinaridade valorizam a questão ambiental, rompendo fronteiras padronizadas, dedicando-se às características, aos estudos e aos processos dos elementos e da sociedade".

Como se percebe, discussões conceituais estão necessariamente vinculadas a modos de interpretar a realidade. O conceito é uma "representação mental abstrata e constitui uma definição operacional de origem teórica, que adquire sentido no âmbito de uma problemática. É sempre uma reconstituição analítica do mundo". (BAILLY \& FERRAS, 2001, p. 19).

rechazar la influencia de los (des) articuladores externos. El paisaje, es así, el fundamento de la formación de las identidades. El paisaje integra el lenguaje científico con el emocional, permitiendo el reforzamiento mutuo entre el saber geográfico y la identidade cultural" (MATEO RODRIGUEZ, 2005; p. 1).

REVISTA GEONORTE, V.9, N.33, p.16-36, 2018.

DOI: 10.21170/geonorte.2018.V.9.N.33.16.36

(ISSN 2237 - 1419) 
AS NOÇÕES DE PAISAGEM: UMA ABORDAGEM MULTIDISCIPLINAR PARA O DIAGNÓSTICO AMBIENTAL E A GESTÃO TERRITORIAL

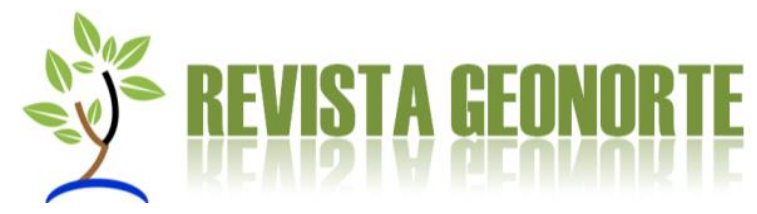

Os conceitos, como sugeridos pelos autores, possuem fundamentos epistemológicos e adquirem significado no âmbito de sistemas explicativos de conjuntos definidos de fenômenos. Porém, um determinado conjunto de fenômenos pode estar sujeito a explicações teóricas diferenciadas, utilizando-se de princípios e conceitos próprios, o que origina enfoques teórico-metodológicos diversificados, mesmo no interior de uma disciplina.

Estudar paisagem, no contexto atual, envolve, pois, a compreensão da pluralidade conceitual. Foi pensando em investigar, de forma crítica, sobre essa pluralidade conceitual e sobre a variedade de noções presentes no escopo geográfico de estudos sobre a paisagem e nas influências diversas que alteram as concepções de diagnósticos, planejamento ambiental e gestão territorial, que se iniciou este trabalho.

Justifica-se a relevância, do trabalho, tendo em vista a aplicação dos estudos geográficos pertinentes ao espaço, à configuração territorial e à paisagem, que lidam com as bases conceituais e as estratégias metodológicas, de interface com outras ciências, tais como: ecologia e geoecologia, fenomenologia e estudos da percepção, psicologia, geologia, economia, arquitetura e urbanismo, hidrologia e pedologia, biogeografia, entre outras áreas que visam o entendimento dos aspectos sociais e políticos, na relação sociedade, cultura e natureza.

Justifica-se, ainda nesta análise, a abordagem multidisciplinar que em sua aplicação de intervenção na paisagem, nos planejamentos e na gestão territorial, precisam lidar com ferramentas analíticas e conhecimentos técnicos, de diversos campos científicos.

\section{MATERIAIS E MÉTODOS}

Como referência teórica, a metodologia, fundamentou-se in "métodos qualitativos", de Alami; Desjeux; Garabuau-Moussaoui (2010), que, de forma adaptada, inseriu os métodos das três análises: temática, descritiva e explicativa, aos procedimentos técnicos de dois níveis de leitura sugeridos por Adler e Doren (2010): a leitura analítica e a leitura sintópica - que ao identificar aspectos relevantes convergentes e divergentes entre autores, objetiva esclarecer questões e organizar a discussão. Essas leituras deram suporte à sustentação do método hermenêutico, para a reflexão.

A metodologia previu objetivar o tema sobre o qual trabalha, limitando os julgamentos de valor e desdobrando o problema - o que se pode chamar de "desconstrução". Uma forma de alcance foi trabalhar com as estratégias analíticas dos diferentes autores e em seguida, com suas representações. Nas representações, distinguem-se as diferentes percepções - como eles veem ou descrevem alguma coisa -, os julgamentos firmados sobre suas percepções - e seus imaginários - o sentido que atribuem às mesmas. Essas distinções são fundamentais ao longo de todo o itinerário de pesquisa qualitativa, quer se trate da construção da problemática, do campo temático de análise e interpretação e da reconstituição dos resultados.

De natureza analítico-interpretativa e multidisciplinar, a metodologia possibilitou verificar no contexto histórico, político, econômico e social, as variações da noção de paisagem, cuja noção construída culturalmente e projetada na sociedade, está em 
AS NOÇÕES DE PAISAGEM: UMA ABORDAGEM MULTIDISCIPLINAR PARA O DIAGNÓSTICO AMBIENTAL E A GESTÃO TERRITORIAL

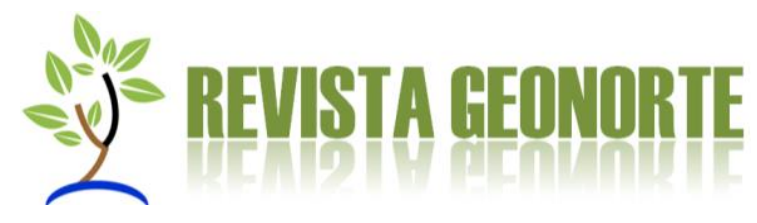

constante transformação, pois é no âmbito social que tem seu ponto de mutação. A análise epistemológica norteou a discussão, a partir da reflexão sobre a fenomenologia da percepção e suas influências na construção de um escopo geográfico da paisagem abstrata, de noção conceitual e concreta que possibilite a realização de diagnósticos e a consolidação de planejamento e gestão territorial.

Quanto aos materiais utilizados para fundamentação e construção do escopo teórico, optou-se por obras completas de autores que trataram da complexidade temática, do ponto de vista histórico, ecológico e sociocultural da paisagem; periódicos de abordagem multidisciplinar e artigos de especialistas de áreas distintas, priorizando a heterogeneidade de ideias. Do ponto de vista experimental, as referências teóricometodológicas, foram extraídas de debates e notas bibliográficas, durante seminários realizados no curso de Doutorado, na Universidade Federal do Paraná, no Programa de Pós-graduação em Geografia, coordenados por Salinas (2016) e Nucci (2017).

Para o procedimento de redação, do ponto de vista estrutural, o texto foi organizado da seguinte maneira: introdução com apresentação de objetivos e de justificativa do trabalho, métodos, materiais utilizados e resultados da revisão bibliográfica; o corpus teórico, desenvolvimento do trabalho propriamente dito, de forma mais densa, fundamenta-se em abordagens analíticas sobre fenomenologia da percepção, concepções histórico-geográficas e geoecológicas de paisagem, além da caracterização da paisagem como integração física e como sistema de conceitos, na instrumentalização do diagnóstico e da gestão territorial. As conclusões antecedem as referências bibliográficas.

\section{RESULTADOS E DISCUSSÕES}

A pesquisa possibilitou verificar a complexidade da noção de paisagem, a partir dos autores selecionados, para análise. Ao selecionar os autores, que tratam da temática, em questão, optou-se por autores que contribuem de alguma maneira, com a abordagem proposta neste trabalho.

Visando uma abordagem multidisciplinar para o estudo da paisagem, buscou-se o diálogo de saberes entre campos analíticos diversos. Verificou-se que, para alguns autores, a paisagem configurou-se como um conceito polissêmico. Para outros, configurou-se como noção. Entretanto, grande parte destes, analisou a paisagem sob o ponto de vista de uma evolução histórica e social, cuja definição se produziu no seio da própria cultura que a produziu.

Durante a análise percebeu-se que, o estudo da paisagem atrelada à Ecologia ainda é bastante difundido, sob a ótica de ecossistemas e/ou ecótopos. Do ponto de vista geográfico, o enfoque para a paisagem é geossistêmico.

Quando se trata de diagnósticos e gestão territorial, as unidades ambientais são imprescindíveis, na formação do escopo de análise. Nesse sentido, as paisagens concretas - concebidas como integração física, revelam um sistema de conceitos, com valores que podem ser compreendidos como escalas de grandeza. 
AS NOÇÕES DE PAISAGEM: UMA ABORDAGEM MULTIDISCIPLINAR PARA O DIAGNÓSTICO AMBIENTAL E A GESTÃO TERRITORIAL

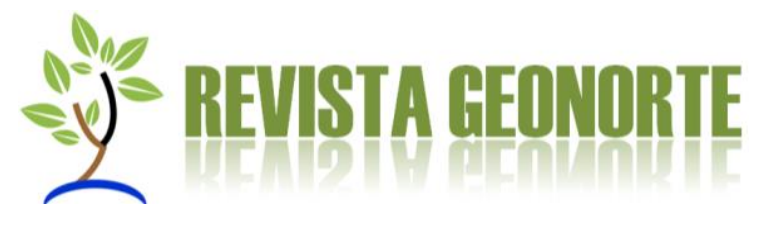

A revisão bibliográfica confirmou, o quão complexo e emblemático é definir paisagem, tendo em vista que, seu significado é carregado de simbolismo e representações, tanto do ponto de vista de sua percepção subjetiva, quanto de sua percepção objetiva.

Essa afirmação torna-se ainda, mais complexa, quando se observa, no mundo atual, a sociedade de riscos, cujas paisagens naturais, ambientais e antrópicas, estão ameaçadas por riscos e estresses, com impactos cada vez mais, avassaladores.

A real situação impõe a mitigação desses impactos e a emergência de uma educação para o risco. Por isso, justifica-se uma abordagem multidisciplinar para os diagnósticos das paisagens e para uma gestão territorial, de risco.

A seguir, são apresentados os resultados analíticos das pesquisas bibliográficas e da sua relação com a problemática proposta. A análise viabilizou a reflexão, a partir da visão crítica, com abertura de ideias ao debate, compreendendo-se que, mesmo que tenha sido concluído um trabalho, a discussão não se encerra, pois, cientificamente, abre-se para novas reflexões.

\section{FENOMENOLOGIA DA PERCEPÇÃO}

A percepção passa pelos sentidos, pelas experiências sensoriais, pela capacidade de abstração do observador que mira a paisagem. Mas, sempre, a partir de seu campo de visão, de sua subjetividade. Pode-se dizer que a percepção é pessoal, intransferível. Há várias formas de visão. Pessoas diferentes têm versões diferentes, do mesmo fenômeno observado. Alguns veem a paisagem e a definem pelo volume. No entanto, a paisagem não é formada de volumes, apenas. Mas de cores, movimentos, odores, sons, entre outros elementos que a constituem. O horizonte vislumbrado não se rompe, quando se aproxima ou se distancia dele. Existe, em si mesmo, em suas fases, em seus ciclos e em suas transformações, porque esses movimentos o constituem independente, do observador.

A dimensão da paisagem é a dimensão da percepção, que é sempre um processo seletivo de apreensão da realidade. Sendo assim, o cognitivo tem importância crucial nessa apreensão, que se faz de forma seletiva. Por isso, a paisagem, vista sob a ótica científica precisa ser investigada, por um olhar criterioso, profundo e metodológico. Para gerar conhecimento que possa ser explicitado, é preciso ir além de uma percepção imediata, pois o conhecimento requer interpretação válida. Só se torna válido, o que antes, aparente, se comprova como verdadeiro.

Identificar, classificar e explicar uma paisagem vai além do domínio da visão, como registro fotográfico. Há várias possibilidades de reconhecer paisagens através de outros sentidos. É possível analisar alguns exemplos. Não é apenas a percepção da coloração da água que diz ser ou não ser um rio poluído. Não é apenas o verde dominante das florestas que nos diz ser ou não ser floresta. Mas a biodiversidade, presente nela.

As condições climáticas, a variação ou não do solo, a capacidade hídrica e sua drenagem, os elementos de flora e fauna, que proporcionam o equilíbrio e permanência da situação favorável à constituição da vida, muito anterior às ações 
AS NOÇÕES DE PAISAGEM: UMA ABORDAGEM MULTIDISCIPLINAR PARA O DIAGNÓSTICO AMBIENTAL E A GESTÃO TERRITORIAL

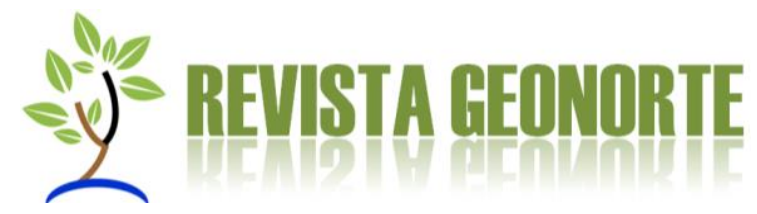

antropogênicas de consumo extremo são possibilidades de análise. Todas essas potencialidades são elementos fundamentais na definição das paisagens. $O$ movimento, os sons, os odores, o sabor, são percebidos na paisagem e captados a partir da experiência.

A percepção envolve a profundidade do ser e é multissensorial. Transcende a superficialidade e a subjetividade, abarcadas pela vista, que se manifestam de forma súbita e imediata. Sobre essa questão, o arquiteto filandês, Pallasmaa (2011 [1996²]) abriu uma discussão inédita, ao falar dos críticos da priorização dos olhos, dos espaços da memória e imaginação na arquitetura dos sentidos. Depois de escrever diversos artigos sobre Filosofia da Cultura, Psicologia Ecológica, Teorias da Arquitetura e Arte, publicou o livro "Os Olhos da Pele - Arquitetura e os Sentidos" que nasceu de "Questões de percepção", como um argumento claro e ajustado em favor das decisivas dimensões fenomenológicas da experiência humana.

Pallasmaa (2011) fundamentou suas explicações na transcendência dos sentidos, no âmbito da Filosofia, partindo de experiências, opiniões e especulações pessoais. Sua preocupação estava no predomínio da vista como supressão dos outros sentidos, influenciando a forma de pensar, ensinar e fazer crítica. De acordo com suas convicções, a hegemonia da vista, sem interação natural com os outros sentidos, reduz e restringe a experiência do mundo à esfera da visão. Essa separação e redução fragmentam a complexidade, a globalidade e a plasticidade inatas do sistema perceptivo reforçando a sensação de distanciamento e alienação.

Ao refletir sobre as emoções e suas associações ao espaço, as quais incitam e emancipam percepções e pensamentos, Pallasmaa (2011) enfatizou que é necessário "Tocar el mundo" e confirmar as suposições sobre o papel do corpo "como local de percepção, pensamento e consciência e o significado dos sentidos na articulação, na armazenagem e no processamento das respostas sensoriais e dos pensamentos". Sobre os sentidos e a primazia do tato, esclareceu:

\begin{abstract}
Todos os sentidos incluindo a visão são extensões do tato; os sentidos são especializações do tecido cutâneo, e todas as experiências sensoriais são variantes do tato $\mathrm{e}$, portanto, relacionadas à tatilidade. Nosso contato com o mundo se dá na linha divisória de nossas identidades pessoais, pelas partes especializadas de nossa membrana de revestimento (...). "O tato é o modo sensorial que integra nossa experiência de mundo com nossa individualidade" (PALLASMAA, 2011, p. 10).
\end{abstract}

$\mathrm{O}$ arquiteto analisou, ainda, sobre o papel da visão periférica afocal na vivência do mundo e na experiência da interioridade dos espaços habitados. Relatou que existem provas médicas de que a visão periférica tem mais importância em nosso sistema perceptivo e mental. A percepção periférica inconsciente transforma a Gestalt retiniana em experiências espaciais e corporais e nos integra ao espaço, abrindo novos campos de visão e pensamento, liberados do desejo implícito de controle e poder do "olho". A experiência multissensorial, na arquitetura dos sentidos, é condição para a consciência do nosso "Ser-no-mundo".

\footnotetext{
${ }^{2}$ A obra de Pallasmaa Juhani foi publicada originalmente em 1996. Sob o título The Eyes of the Skin: Architecture and the Senses, $2^{\text {nd }}$ edition ISBN 0470015799/ 9780470015797, 2005. Na versão portuguesa, a obra Consultada é de 2011.
}

REVISTA GEONORTE, V.9, N.33, p.16-36, 2018.

DOI: 10.21170/geonorte.2018.V.9.N.33.16.36

(ISSN 2237 - 1419) 
AS NOÇÕES DE PAISAGEM: UMA ABORDAGEM MULTIDISCIPLINAR PARA O DIAGNÓSTICO AMBIENTAL E A GESTÃO TERRITORIAL

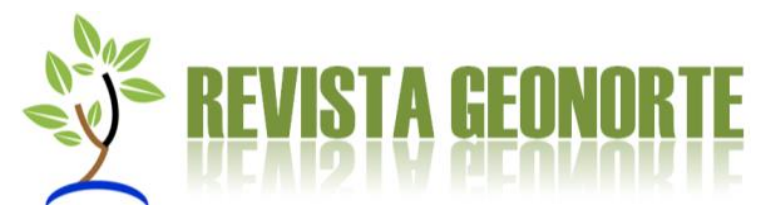

A obra de Pallasmaa tornou-se um clássico mundial e influenciou o estudo da paisagem cultural, construída e captada pela fenomenologia da percepção. Uma de suas referências foi Merleau-Ponty (1908-1961) e sua reflexão sobre o visível e o invisível, "horizonte das coisas" como possibilidade lógica de concepção. MerleauPonty, assim como outros estudiosos da Fenomenologia da Percepção, influenciaram os estudos de percepção da paisagem. Mas, há um ponto de distinção do sentido de paisagem da arquitetura do corpo e de paisagem espacial focada na superfície terrestre, apesar das correlações entre subjetividade e objetividade.

Vale dizer que, a fenomenologia é "o estudo das essências, e todos os problemas, segundo ela, resumem-se em definir essências: a essência da percepção, a essência da consciência, por exemplo" (MERLEAU-PONTY, 2011, p. 1), mas a fenomenologia é também, como afirmou o autor, uma filosofia que repõe as essências na existência, e não pensa que se possa compreender o homem e o mundo de outra maneira senão a partir de sua "facticidade". É uma "filosofia transcendental que coloca em suspenso, para compreendê-las, as afirmações da atitude natural", mas é também uma filosofia para a qual o mundo já está sempre "ali", "antes da reflexão, como uma presença inalienável, e cujo esforço todo consiste em reencontrar este contato ingênuo com o mundo, para dar-Ihe enfim um estatuto filosófico".

Merleau-Ponty (2011), ainda salientou que:

\begin{abstract}
É a ambição de uma filosofia que seja uma "ciência exata", mas é também um relato do espaço, do tempo, do mundo "vividos". É a tentativa de uma descrição direta de nossa experiência tal como ela é e sem nenhuma deferência à sua gênese psicológica e às explicações causais que o cientista, o historiador ou o sociólogo dela possam fornecer, e, todavia Husserl, em seus últimos trabalhos, menciona uma "fenomenologia genética" e mesmo uma "fenomenologia construtiva" (MERLEAU-PONTY, 2011, p. 1-2).
\end{abstract}

A Arquitetura da Paisagem e a Fenomenologia da Percepção são contribuições valiosas para o conhecimento geográfico da paisagem. Houve um tempo em que, para muitos, a Geografia teria como objeto o estudo da paisagem. Entretanto, há várias formas para se estudar a paisagem e o estudo da paisagem não é um objeto-domínio da Geografia. Seguinot (1996) apresentou como componente imperativo que auxilia na definição do padrão e dos valores de ordem socioeconômica, a paisagem natural modificada. Estudou a construção arquitetônica dos espaços, tomando como referência da investigação: a altura, a distância entre os objetos e os espaços ocupados, os materiais utilizados, os detalhes decorativos, o espaço interior e a ecologia do entorno.

\title{
CONCEPÇÕES HISTÓRICO-GEOGRÁFICAS DE PAISAGEM
}

$\mathrm{Na}$ obra "A natureza do espaço: técnica, e tempo, razão e emoção", publicada originalmente, como $1^{1}$ edição, por Santos (1996), houve distinção entre espaço e paisagem, pois "não são sinônimos". Ao fazer referência à paisagem, o autor a definiu como "um conjunto de formas, que num dado momento, exprime as heranças que representam as sucessivas relações localizadas entre homem e natureza". A palavra paisagem, como informou, é frequentemente utilizada em vez da expressão 
AS NOÇÕES DE PAISAGEM: UMA ABORDAGEM MULTIDISCIPLINAR PARA O DIAGNÓSTICO AMBIENTAL E A GESTÃO TERRITORIAL

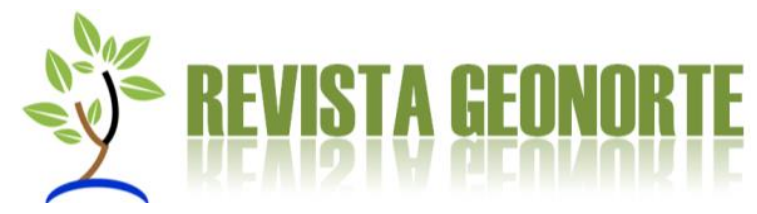

configuração territorial. Esta é o "conjunto de elementos naturais e artificiais que fisicamente caracterizam uma área". "A rigor, a paisagem é apenas a porção da configuração territorial que é possível abarcar com a 'visão'. Assim, quando se fala em paisagem, há, também, referência à configuração territorial e, em muitos idiomas, o uso das duas expressões é indiferente" (SANTOS, 2012, p. 103) ${ }^{3}$.

A paisagem, como explicou Santos (2012) se dá como:

Um conjunto de objetos reais-concretos. Nesse sentido a paisagem é
transtemporal, juntando objetos passados e presentes, uma construção
transversal. Cada paisagem se caracteriza por uma dada distribuição de
formas-objetos, providas de um conteúdo técnico específico. A paisagem é,
pois, um sistema material e, nessa condição, relativamente imutável
(SANTOS, 2012, p. 103-104).

A paisagem existe através de suas formas, criadas em momentos históricos diferentes, porém coexistindo no momento atual. No espaço, as formas de que se compõe a paisagem preenchem, no momento atual, como resposta às necessidades atuais da sociedade. Tais formas nasceram sob as diferentes necessidades, emanaram de sociedades sucessivas, mas só as formas mais recentes correspondem a determinações da sociedade atual.

Sob a perspectiva geográfica, a definição de paisagem está inserida no conceito de espaço, podendo se originar de uma visão contemplativa, descritiva ou explicativa. Quando interpretada e representada está associada a várias concepções. Como objeto de conhecimento está no centro das preocupações de variados profissionais. $\mathrm{Na}$ visão geográfica, paisagem e espaço resultam de movimentos da sociedade e são constituídos como um mosaico de relações, formas, funções e sentidos. A paisagem natural transformada pela sociedade e marcada pela herança cultural, como foi analisada por Aziz Ab'Sáber (2003, p. 9) está impregnada de símbolos, valores e representações.

Como afirmou Vitte (2007): "a categoria paisagem se insere no debate sobre a complexidade da abordagem integrada entre a natureza e a cultura nas ciências sociais". Segundo este autor, uma reflexão sobre o conceito de paisagem remete-nos a discussão "sobre o olhar geográfico e sobre a formação das bases constitutivas da cognição, assim como a construção do/no imaginário coletivo da paisagem enquanto elemento de articulação do processo de pertencimento do ator social a um determinado lugar". Assim, a paisagem emerge na análise geográfica carregada de simbolismo, "sendo responsável pela constituição do imaginário social que atua na condução da ação dos atores sociais, ao mesmo tempo em que mediatiza a representação do território por estes mesmos atores" (VITTE, 2007, p. 71).

No artigo La Concepcion Sobre Los Paisajes Vista Desde La Geografia, Mateo Rodriguez (2005, p. 1-29) analisou e fez uma síntese das diferentes acepções de paisagens, como fundamentos de base para uma teoria das paisagens geográficas. A noção de paisagem natural originou-se na "Geografia Tradicional" e foi desenvolvida

\footnotetext{
${ }^{3}$ A obra "A natureza do espaço: técnica, e tempo, razão e emoção", referida aqui foi publicada originalmente em 1996. Entretanto, a obra consultada neste trabalho, foi reeditada em 2012, em São Paulo, pela EDUSP - Editora da Universidade de São Paulo (4 ${ }^{\underline{a}}$ Edição, $7^{a}$ Reimpressão), da (Coleção Milton Santos; 1 ).
}

REVISTA GEONORTE, V.9, N.33, p.16-36, 2018.

DOI: 10.21170/geonorte.2018.V.9.N.33.16.36

(ISSN 2237 - 1419) 
AS NOÇÕES DE PAISAGEM: UMA ABORDAGEM MULTIDISCIPLINAR PARA O DIAGNÓSTICO AMBIENTAL E A GESTÃO TERRITORIAL

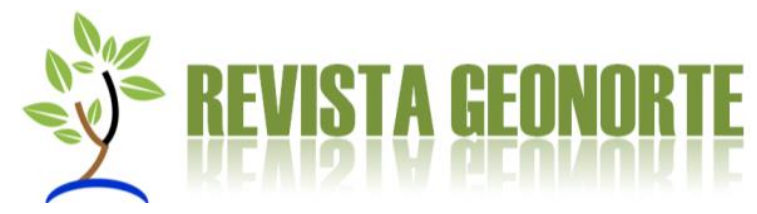

como "Geografia das Paisagens" pelos russos de visão naturalista, nos fins do século XIX. As unidades naturais existentes, influenciadas por físico-naturais, de totalidade dialética, formavam o sistema natural. Como paradigma "determinista natural ou ambiental" foi resgatado, depois da década de 1960, pelo geógrafo soviético Víctor Sochava (1978) na "Teoria Geral de Sistemas", quando lançou o conceito de "geossistema natural".

A paisagem da "Geografia Neopositivista Clássica", baseada no conceito de Landschaft, da cultura alemã foi introduzida por S. Passarge e por O. Schluter. Nessa visão distinguia-se paisagem original, de caráter natural e paisagem cultural, resultante da dialética entre "povo" e "território". De tradição hegeliana, reconhecia a simbiose entre "raça, civilização e território", originando três desdobramentos, como explicou Mateo Rodrigues (2005):

\begin{abstract}
- a concepção "regionalista", dando origem aos estudos regionais, na Geografia Humana ou Cultural, desenvolvida pelo geógrafo norte-americano Harsthorne. Esse fundamentou suas ideias em Hettner (1920). Para esse autor, as regiões eram consideradas "fragmentos de terra", delimitadas arbitrariamente. Os limites delimitados no espaço eram produtos da racionalidade humana. $\mathrm{O}$ método regional era formado por procedimentos intelectuais precisos para a construção de áreas e poderia ser estudado por diversas disciplinas;
\end{abstract}

\begin{abstract}
- a concepção de espaço-paisagem, considerava a paisagem como espaço natural individualizado e identificava a singularidade do povo alemão. A simbiose povo-espaço manifestava-se como uma paisagem aparente, tornando a nação alemã, um território próprio, uma identidade, como espaço nacional, subjetiva. Por sua interpretação radical, deu origem ao nazismo;
\end{abstract}

- a paisagem cultural desenvolvida por Carl Sauer (1925), geógrafo alemão naturalizado norte-americano, fundador da Escola de Berkeley, no início do século XX. Para Sauer, a paisagem "é a imagem que apresenta o espaço em uma área determinada e que permite individualizá-lo". A paisagem "outorga personalidade ao espaço, considerando-se como uma totalidade que resulta da combinação de múltiplos elementos físicos e humanos e de uma trajetória histórica: síntese da ação cultural de um grupo social, interpretada como um organismo completo, resultado da ação da cultura ao longo do tempo, sobre a paisagem natural" (MATEO RODRIGUEZ, 2005, p. 2-4).

Mateo Rodriguez (2005) fez referência também, à paisagem do "possibilismo". Fundamentada na "Geografia Humana da Escola Francesa de Vidal de La Blache" (1930) e na formulação teórico-conceitual do historiador Lucien Febvre, a "relação homem-natureza", como objeto da Geografia, considerava a paisagem como "área de ocorrência de uma forma e um gênero de vida - acervo técnico ou conjunto de técnicas, hábitos, usos e costumes que permitem ao homem utilizar os recursos naturais disponíveis". Dos diversos meios e técnicas surgiam diversos gêneros de vida. A Geografia Regional originou-se nesse contexto, com estudos exaustivos de monografias geográficas de Ecologia Humana e com registro sobre agrupamentos humanos, que humanizaram o meio natural e criaram o meio geográfico.

A paisagem da "Nova Geografia", uma forma de racionalismo renovado, objetivou o estudo das regularidades espaciais associadas à distribuição dos fenômenos geográficos no espaço. Como fenômeno geométrico de noção operativa e instrumental ganhou nova forma: "a da matematização" das estruturas espaciais. O 
AS NOÇÕES DE PAISAGEM: UMA ABORDAGEM MULTIDISCIPLINAR PARA O DIAGNÓSTICO AMBIENTAL E A GESTÃO TERRITORIAL

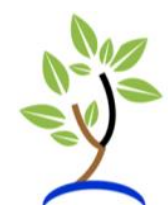

paradigma da Nova Geografia ou paradigma da Geografia Quantitativa foi consolidado em meados do século XX. Tinha como base "os espaços relativos, de padrão espacial resultante das decisões sociais". A delimitação das áreas espaciais se dava através de métodos matemáticos e quantitativos (MATEO RODRIGUES, 2005, p. 6).

A "Geografia Humanística" surgiu nos anos 1970, fazendo uma crítica "à racionalidade geométrica do espaço e ao positivismo naturalista. Foi identificada, também, como "Geografias do Sujeito" (Geografia Humanística Pós-Moderna)". Essa se fundamentou nas "filosofias idealistas do sujeito, em particular as filosofias do significado, a fenomenologia e o existencialismo". Essa temática de paisagem apontou uma diferente realidade, "com aspectos psicológicos". Como esclareceu Mateo Rodriguez (2005, p. 6-7), "Tuan (1974) baseava-se em abordagens da percepção e estudo de mundos individuais, atitudes e sentimentos sobre o meio". Fundamentava-se em "subjetividade, intuição, sentimentos, simbolismo, sensações e valores dos seres humanos. Os lugares, espaços vividos, eram associados à experiência particular".

O autor esclareceu sobre outras duas grandes influências, como desdobramentos paradigmáticos, envolvendo o meio natural e o meio cultural:

- O paradigma "ambiental", construído em contraposição ao paradigma racionalista metafísico dominou a ciência a partir do século XIX. Partiu das concepções da Ecogeografia de Jean Tricart na década de 1960, na França, da Geoecologia formulada na Alemanha por Karl Troll e da Geografia dos Landschafts, dos geógrafos soviéticos e de outros países da Europa. A paisagem natural, como categoria fundamental de estudo, privilegiou a articulação espaço-temporal das diferentes categorias de sistemas ambientais, em espaços concretos. Representantes desse paradigma aceitaram as três interpretações de paisagem: natural, social e cultural. A regionalização foi considerada como uma individualização espacial, em suas variantes: econômica, política, administrativa, natural, geoecológica.

- A vertente marxista libertária, na "Geografia Crítica" visou atuar sobre a estrutura econômica, responsável pelas demais estruturas constitutivas da sociedade capitalista, objeto central de crítica do marxismo estruturalista. Como corrente radical essa corrente da Geografia, pós década de 1970, considerava a transformação político-social como ponto central, em relação à superfície terrestre. O objeto de estudo, a organização da sociedade espacializada, foi considerada uma dimensão da totalidade espacial e o espaço um instrumento de reprodução do sistema social e produção de mais-valia.

Recentemente, encontram-se várias tendências de análise sobre a paisagem. Porém, as noções principais, se desdobraram em duas grandes temáticas:

A paisagem natural se concebe como uma realidade, cujos elementos estão
dispostos de maneira tal que subsistem desde o todo e o todo, subsiste desde
os elementos, não como objetos caoticamente mesclados, mas como
conexões harmônicas de estrutura e função. A paisagem é assim: um espaço
físico e um sistema de recursos naturais nos quais se integram as
sociedades, em um binômio inseparável entre a Sociedade e a Natureza. A
paisagem cultural é uma noção transdisciplinar que reflete um nível de
organização mais complexa e superior que a paisagem natural e o social. E
que incorpora e implica uma participação substantiva da sociedade. Visto

REVISTA GEONORTE, V.9, N.33, p.16-36, 2018.

DOI: 10.21170/geonorte.2018.V.9.N.33.16.36

(ISSN 2237 - 1419) 
AS NOÇÕES DE PAISAGEM: UMA ABORDAGEM MULTIDISCIPLINAR PARA O DIAGNÓSTICO AMBIENTAL E A GESTÃO TERRITORIAL

assim, a paisagem cultural constitui um binômio inseparável entre os sistemas ou geossistemas naturais e sociais. Estudar a paisagem cultural implica a sua relação com a paisagem natural, que é transformada durante o processo cultural, tendo em vista que, a sociedade se projeta na Natureza, para uso de seus recursos e para planejar a gestão do espaço e do território. Há, portanto, uma inter-relação social e política, no processo de alteração da paisagem natural, definida por meio de limites políticos e jurídicos, na construção das sociedades (MATEO RODRIGUES, 2005, p. 10).

Como se verifica, na explicação do autor, nota-se a complexidade da noção conceitual de paisagem, mesmo nas duas grandes temáticas atuais. É possível, dizer a partir de suas ideias, sobre a relevância do "paradigma da complexidade", que auxilia no entendimento da definição e territorialização da paisagem, como instrumento de gestão territorial, sob a perspectiva de uma abordagem multidisciplinar.

\section{PAISAGEM GEOECOLÓGICA}

A Geografia associa-se mais, à ideia da Ecologia da Paisagem, quando necessita fazer um estudo mais profundo de identificação, classificação e mapeamento, tendo em vista a sua extensão e complexidade de análise. O objeto paisagem na Geografia transcende a escala sensorial-afetiva. De acordo com Nucci et al. (2014), a palavra paisagem contém uma característica fundamental que a torna um ponto de partida para a interpretação do meio. Ou seja, ela é acessível aos órgãos dos sentidos, dos seres humanos, principalmente à visão. Mas, a paisagem entendida "como um cenário sem vida, sem movimento, como uma pintura ou um quadro, seria mesmo, apenas o ponto de partida".

De acordo com Claval (2002, p. 21), "atualmente, os geógrafos analisam a relação homem/meio ambiente segundo a perspectiva ecológica: a transferência de energia solar de um ser a outro através das cadeias tróficas; os ciclos das matérias". Entretanto, "a dimensão ecológica da Geografia Humana tornou-se uma preocupação central da disciplina. Ela deve ser conduzida numa perspectiva crítica" (CLAVAL, 2002, p. 26).

Para Monteiro (2000), a paisagem é:

Entendida como o resultado de integração dinâmica dos elementos de suporte e cobertura (físicos, biológicos e antrópicos), sendo expressa em partes delimitáveis infinitamente, mas individualizadas por meio das relações entre elas, que organizam um complexo (sistema) conjunto em perpétua evolução. (MONTEIRO, 2000, p. 39 apud Mateo Rodrigues).

A palavra sistema foi incorporada por várias ciências. Na Geografia, na forma do termo geossistema e na Ecologia, na forma do termo ecossistema. Nesse sentido, é possível analisar a paisagem, assim como o espaço geográfico que a contém, de forma integrada, global e sistêmica. Olhar a paisagem, segundo a visão sistêmica é procurar entender não somente as formas e as estruturas da paisagem, mas também, a dinâmica e sua evolução: atitude fundamental na construção dos conhecimentos sobre as relações entre a natureza e a sociedade humana. 
AS NOÇÕES DE PAISAGEM: UMA ABORDAGEM MULTIDISCIPLINAR PARA O DIAGNÓSTICO AMBIENTAL E A GESTÃO TERRITORIAL

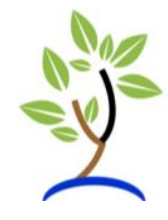

Christofoletti (1999, p. 35) definiu e caracterizou sistemas ambientais. Segundo ele, "os sistemas ambientais representam entidades organizadas na superfície terrestre, de modo que a espacialidade se torna uma das suas características inerentes" e a "organização desses sistemas vincula-se com a estruturação e funcionamento de (e entre) seus elementos, assim como resulta da dinâmica evolutiva". Em virtude da variedade de elementos componentes e dos fluxos de interação, constituem exemplos de sistemas complexos espaciais.

O autor fez alusão aos elementos componentes, definindo as variáveis relevantes e considerando os fluxos de matéria e energia nos ecossistemas e geossistemas "entidades representativas de sistemas ambientais, incorporados na modelagem, instrumento de análise no estudo desses sistemas, no contexto das diversas escalas de grandeza espacial e temporal que podem ser focalizadas". Os ecossistemas correspondem "aos sistemas ambientais biológicos, isto é, constituídos em função dos seres vivos e sob a perspectiva ecológica, enquanto os geossistemas correspondem aos sistemas ambientais para as sociedades humanas" (CHRISTOFOLETTI, 1999, p. 35) sendo constituídos pelos elementos físicos e biológicos da natureza e analisados sob a perspectiva geográfica.

$\mathrm{Na}$ visão de Santos (2004) para aplicar os conceitos da ecologia da paisagem em planejamento, "deve-se considerar que essa teoria vem sendo desenvolvida em diferentes campos de conhecimento, com princípios, conceitos e estratégias próprios" (SANTOS, 2004, p. 144). Consequentemente, "desenvolveram-se diversos procedimentos sob a ótica de diferentes profissionais, cada qual levando a um resultado particular".

A ecologia da paisagem, como afirmou a autora (2004, p. 146), "pela própria variedade de concepções, utiliza diferentes caminhos metodológicos. Os principais definem as unidades de paisagem a partir de avaliações espaciais". Sob a abordagem geográfica, o primeiro passo metodológico é identificar os condicionantes (ou indicadores do meio) da paisagem por meio de um "diagnóstico global de cenário passado e presente. Os condicionantes refletem as características próprias a um diagnóstico ambiental, ou seja, a potencialidade, fragilidade, acertos e conflitos" (SANTOS, 2004, p. 146).

Fazer diagnóstico global de cenário passado e presente, para identificar potencialidades e conflitos é um desafio ambiental. "No período de globalização neoliberal, a natureza é considerada como uma fonte inesgotável de recursos, conforme visão do fordismo e sua crença numa sociedade de consumo de massas ilimitada", como salientou Porto-Gonçalves (2012, p. 61).

Para esse autor, "o desafio ambiental está no centro das contradições do mundo moderno-colonial. Afinal, a ideia de progresso e, sua versão mais atual, o desenvolvimento é, rigorosamente, sinônimo de dominação da natureza! " Além do desafio ambiental e tecnocientífico, verifica-se um desafio político e, civilizatório. A ideia de desenvolvimento, como argumentou, "sintetiza melhor que qualquer outra o projeto civilizatório que, tanto pela via liberal e capitalista, como pela via socialdemocrata e socialista, a Europa Ocidental acreditou poder universalizar-se" (PORTOGONÇALVES, 2012, p. 61-62). 
AS NOÇÕES DE PAISAGEM: UMA ABORDAGEM MULTIDISCIPLINAR PARA O DIAGNÓSTICO AMBIENTAL E A GESTÃO TERRITORIAL

\section{㭴}

\section{PAISAGEM COMO INTEGRAÇÃO FÍSICA: UM SISTEMA DE CONCEITOS}

A paisagem analisada como integração física e como sistema de conceitos associase, analiticamente, aos aspectos sociais. Nesse sentido, a concepção de paisagem é holística e multidisciplinar, podendo ser analisada em sua particularidade, como aspecto externo de uma área - o território, cuja paisagem é visual, como formação natural, como formação antroponatural, como sistema econômico-social e sob a ótica cultural.

Para Salinas (2016) o funcionamento da paisagem ecológica, vista como algo objetivo, pode ser cartografada, em seus limites. A paisagem real está na base do sistema, tendo como sobreposição as paisagens: natural e antroponatural.

O esquema do sistema de conceitos pode ser representado, como sistema, em sua totalidade ou em suas partes. Mas sempre, como analisou Salinas (2016), com a presença dos elementos antrópicos. "Caracterizados como elementos associados aos elementos naturais, dão um sentido dinâmico à paisagem em sua dimensão morfológica e em sua dimensão fisiológica". Torna-se possível "representar formas e processos dinâmicos, em uma estrutura de funcionamento", cujo sentido aponta significados para perceber "os elementos diferentes, mas associados, interligados, dando existência a uma estrutura flexível e propensa a mudanças e alterações".

Conforme explicou o autor, "a paisagem, além de sua percepção objetiva, concreta e real, pode ser concebida como uma construção subjetiva, baseada em valores e valoração diferentes, de acordo com a cultura". Como exemplo, citou a fotografia que é valorada de forma diferente, a partir do afeto cultural e as simbologias empregadas na representação das paisagens, nos mapeamentos, cujo efeito cultural do emprego das cores: verde, significando vegetação, azul como água ou marrom como terra, estimulam padrões que induzem um ou outro tipo de leitura. Citou ainda, símbolos matemáticos para expressar estatísticas a serem padronizadas, tendo em vista a arbitrariedade da cartografia, que influenciou fatos culturais e históricos.

O conceito espanhol de paisagem se constitui da associação dos elementos principais de formação do sistema em funcionamento (totalidade e partes), em seu caráter objetivo e subjetivo:

É qualquer parte do território tal como é percebida pelas populações, cujo caráter resulta da ação de fatores naturais e lou humanos e suas interpretações (ART 1, 2 - Tradução Minha) ${ }^{4}$.

A visão espanhola direciona o entendimento conceitual para análise da relação entre a Geografia da Paisagem e a Ecologia, ou seja, para a Geoecologia. A ciência da paisagem é, pois, do âmbito da Geografia.

\footnotetext{
${ }^{4}$ No original, lê-se: Es qualquier parte del território tal como es percebida por las poblaciones, cuya carácter resulta de la acción de factores naturales y/o humanos y sus interpretações (ART 1, 2, sem data no original).
} 
AS NOÇÕES DE PAISAGEM: UMA ABORDAGEM MULTIDISCIPLINAR PARA O DIAGNÓSTICO AMBIENTAL E A GESTÃO TERRITORIAL

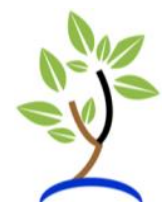

Do ponto de vista do estudo dos componentes físicos: clima, solo, relevo, vegetação, geomorfologia, geologia, hidrografia, a paisagem como componente físico da superfície terrestre está inserida na Geografia Física. Mas, sempre presentes de forma holística e sistêmica, como base de análise de diagnósticos ambientais. Como explica Salinas et al. (2013) as paisagens como unidades de integração de caráter holístico e sistêmico:

\begin{abstract}
constituem a base para a realização de diversas investigações de caráter ambiental, que vão desde a realização dos diagnósticos ambientais até o ordenamento ambiental e territorial, concebido isto a partir do estudo das propriedades e características das unidades de paisagens, o que permite propor as formas de utilização mais adequadas de enfoque de uso racional e diversificado (Bastian \& Steinhardt, 2002; Bertrand \& Bertrand, 2006; Busquet \& Cortina, 2009 y Salinas, et. al., 1993 apud SALINAS et al, 2013, p. 10 Tradução Minha) ${ }^{5}$.
\end{abstract}

Do ponto de vista dos componentes sociais, associados às atividades antrópicas espaciais, o território como espaço de controle e poder é articulado pela Geografia Humana, seja, na dimensão econômica, regional ou cultural, na análise de seu contexto histórico, político ou ideológico.

Torna-se relevante, compreender as mutações estruturais e funcionais, nas variações associadas aos complexos territoriais naturais. Não basta apenas, captar a imagem da paisagem ou contemplá-la, para diagnosticá-la.

\title{
DIAGNÓSTICO AMBIENTAL E GESTÃO TERRITORIAL
}

O diagnóstico ambiental é um método científico de análise da paisagem. Analisa-a, em sua estrutura físico-morfológica e é de grande relevância na gestão territorial. Por lidar com paisagens concretas, investiga e caracteriza as paisagens de forma funcional, visando compreender a sua integração geoecológica. Os diagnósticos são ferramentas úteis, na consolidação de planejamentos visando melhorar as ações do ordenamento e da gestão territorial.

Para a análise das unidades de paisagem e tratamento das informações espaciais, o georreferenciamento e o SIGs - Sistemas de Informações Geográficas são metodologias imprescindíveis. No processo de delimitação e classificação de paisagens, esses recursos favorecem a produção de produtos cartográficos, mapeando dados e informações em diferentes escalas, e a partir de diferentes enfoques.

\footnotetext{
${ }^{5}$ No original lê-se: "Los paisajes como unidades de integración de carácter holístico y sistémico constituyen la base para la realización de diversas investigaciones de carácter ambiental, que van desde la realización de los diagnósticos ambientales hasta el ordenamiento ambiental y territorial, concebido esto a partir del estudio de las propiedades y características de las unidades de paisajes, lo que permite proponer las formas de utilización más adecuadas bajo un enfoque de uso racional y diversificado" (Bastian \& Steinhardt, 2002; Bertrand \& Bertrand, 2006; Busquet \& Cortina, 2009 y Salinas, et al., 1993 apud Salinas et al., 2013, p. 10).
} 
AS NOÇÕES DE PAISAGEM: UMA ABORDAGEM MULTIDISCIPLINAR PARA O DIAGNÓSTICO AMBIENTAL E A GESTÃO TERRITORIAL

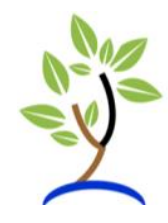

A Cartografia é um elemento chave na representação de paisagens, tendo o mapa científico como referencial associado às pesquisas de campo, tanto na produção de mapas de estudos preliminares quanto em estudos conclusivos, com os mapassíntese. A análise e o tratamento da informação espacial estão conjugados com outros recursos e metodologias como: imagens de satélite, sensoriamento remoto, processamento digital de imagens, informações socioeconômicas, estatística e demais indicadores sociais.

Salinas (2013) apresentou suas ideias a respeito:

\begin{abstract}
Hoje, em dia, existem diversos procedimentos para a realização dos mapas de paisagens, entre os quais estão aqueles que a partir do uso dos Sistemas de Informações Geográficas (SIGs) permitem a obtenção de uma tipificação do território segundo a manifestação das relações entre os componentes naturais e a intervenção humana, gerando mapas preliminares no gabinete que posteriormente são comprovados no campo e se convertem em ferramenta para a gestão do território (SALINAS et al., 2013, p. 11 Tradução minha) ${ }^{6}$.
\end{abstract}

Há uma classificação geral de mapas da paisagem gerada no decorrer do processo, a depender do objetivo do trabalho, como: mapas temáticos, tendo como referência de ponto de partida o mapa principal (a paisagem) e mapas secundários, caracterizados por tipologias e simbologias próprias que auxiliarão na leitura e interpretação das informações representadas e mapeadas. É possível, também, produzir mapas potenciais. O mapa turístico de paisagem, o mapa de ocorrência de recursos minerais, mapas de profundidade (de água), mapas de atividades pesqueiras, mapas de águas termais, mapa de função produtiva (floresta), mapa de função agrícola são alguns exemplos.

Nos procedimentos diagnósticos para o planejamento e ordenamento territorial, os métodos para a caracterização de análise devem ser bem pensados e adequarem à realidade pesquisada. São procedimentos científicos e requerem esse tipo de rigor. É preciso um detalhamento nas proposições e projetos, a partir de inventários de componentes de paisagem que auxiliem na escolha da escala, para obter êxito no trabalho.

Com esses procedimentos metodológico-científicos torna-se relevante contextualizar a análise espaço-temporal, na reconstituição histórica dos processos de modificação natural e antrópica. A utilização de métodos de avaliação de paisagens na fase de sua caracterização, fundamentada em levantamento e informações de campo é de suma importância.

Fatores sociológicos, inventário de paisagens com reconhecimento dos aspectos físicos, atividades agrárias existentes, usos e impactos sobre a paisagem, dados

\footnotetext{
${ }^{6}$ No original, lê-se: "Hoy en día existen diversos procedimientos para la realización de los mapas de paisajes, entre los cuales están aquellos que a partir del uso de los Sistemas de Información Geográfica (SIG) permiten la obtención de una tipificación del territorio según la manifestación de las relaciones entre los componentes naturales y la intervención humana, generando mapas preliminares en el gabinete que posteriormente son comprobados en el campo y se convierten en herramienta para la gestión del territorio" (SALINAS et al., 2013, p. 11).
}

REVISTA GEONORTE, V.9, N.33, p.16-36, 2018.

DOI: 10.21170/geonorte.2018.V.9.N.33.16.36

(ISSN 2237 - 1419) 
AS NOÇÕES DE PAISAGEM: UMA ABORDAGEM MULTIDISCIPLINAR PARA O DIAGNÓSTICO AMBIENTAL E A GESTÃO TERRITORIAL

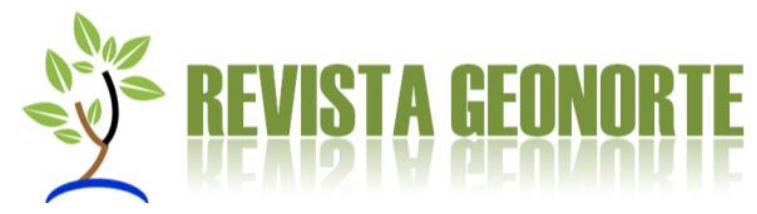

gerais de tipo de solos, tipo de vegetação, variações climáticas, pluviosidade, declividades do terreno, problema principal e problemas secundários estão presentes, no horizonte analítico. Há uma gama de possibilidades. As combinações de informações e mapas agregados, que representam o horizonte de análise visam ainda, formas adequadas de captar, interpretar, agrupar, simplificar.

Para a análise de paisagens sistêmicas ${ }^{7}$, como integração física, o enfoque deve ser estrutural, pois se verifica o funcionamento da paisagem, em sua condição dinâmica e histórico-genético, identificada como antropomorfização. A estrutura aí, entendida, é uma carga de elementos do sistema. A floresta, em sua forma (morfologia) com o seu efeito de borda, pode ser comparada ao sistema, método a ser utilizado para analisar a estrutura morfológica horizontal da paisagem.

Nesse caso, a paisagem-floresta é sistêmica e é representada como um conjunto de pontos na superfície terrestre. A composição funcional dessa paisagem passa a significar um conjunto de polígonos diferentes. Decorrente desse processo, mapas de paisagem do tipo "mosaico" e paisagem "dominante", são gerados em ambiente digital.

Quando se trata de análise da estrutura vertical das paisagens, os métodos para os estudos desse tipo de estrutura geram mapas que expressam frequência, tamanho ou área de relações entre paisagens. São indicadores de representação de fluxos e interrelações. O exemplo, nesse caso, é o manguezal, onde se verifica a frequência de suas relações: umidade do solo, salinização, entre outros fatores.

$\mathrm{Na}$ análise da estrutura vetorial ou funcional, as perguntas para a geração dos mapas estão relacionadas ao funcionamento da paisagem e seus processos físico-químicos. O objetivo é verificar o padrão de sua evolução e de sua dinâmica. O modelo sistêmico de funcionamento do geossistema é que será utilizado nesse tipo de análise.

Para Almeida (2011, p. 332) ao pensar na "instrumentalização do processo de gestão ambiental, no plano de desempenho ambiental, nos sistemas de gestão territorial e gestão da qualidade ambiental, é fácil perceber a importância do ordenamento territorial". Mas, é preciso ter "um bom conhecimento da dinâmica ambiental para que o processo gestor seja considerado pleno no que diz respeito à gestão ambiental".

Segundo ele, "para atingir a sustentabilidade é preciso conhecer e entender a capacidade de suporte do meio físico ou ecológico do ambiente, sendo o trabalho da Geografia Física a estratégia mais adequada para cumprir esse objetivo" (ALMEIDA, 2011, P. 333).

\footnotetext{
${ }^{7}$ A respeito deste tema, leia o livro "Geoecologia das Paisagens: uma visão geossistêmica da análise ambiental" de José Manuel Mateo Rodriguez, Edson Vicente da Silva e Agostinho Paula Brito Cavalcanti. No referido livro, organizado em 222 páginas, os autores apresentam, de forma bem estruturada, abordagens referentes à fundamentação teórica e metodológica da Geoecologia das Paisagens; unidades geoecológicas regionais e locais (regionalização, níveis espaciais, tipologias, propriedades de nível local de diferenciação, geótopo como Unidade Básica de Nível Local de Diferenciação da Paisagem, fatores geoecológicos de formação de paisagens, sistemas de unidades taxonômicas locais e métodos de distinção e cartografia da paisagem); enfoques na análise da paisagem (estrutural, funcional, evolutivo-dinâmico, histórico-antropogênico, integrativo da estabilidade e sustentabilidade).
}

REVISTA GEONORTE, V.9, N.33, p.16-36, 2018.

DOI: 10.21170/geonorte.2018.V.9.N.33.16.36

(ISSN 2237 - 1419) 
AS NOÇÕES DE PAISAGEM: UMA ABORDAGEM MULTIDISCIPLINAR PARA O DIAGNÓSTICO AMBIENTAL E A GESTÃO TERRITORIAL

\section{CONCLUSÃO}

Como se percebeu, os estudos geográficos transcendem a visão de paisagem "que a vista alcança". Se a paisagem fosse de fato, tudo aquilo que vemos, ou tudo aquilo que a nossa visão alcança como é do acordo de vários autores, ela, poderia ser definida então, como domínio do visível, ou seja, aquilo que a vista abarca. Porém, a vista ao abarcar algo, o faz a partir de suas referências perceptuais, dando significado ao que de fato vê, interpretando nuances e buscando compreender a essência. É sempre necessário, aprofundar o olhar e investigar sobre os componentes da paisagem. Mas também, aperfeiçoar os métodos. Para ir mais além, para verificar a estabilidade e a fragilidade natural das paisagens, é preciso verificar a qualidade ecológica e seu potencial, a sensibilidade, a complexidade dos conflitos de usos com as mudanças provenientes do uso do solo e da vegetação.

A situação de riscos, os perigos e as ameaças naturais, assim como os fatores antrópicos, agregados de valoração, a frequência das influências naturais e culturais no processo evolutivo das paisagens, são elementos que orientam os diagnósticos. Para isso, o cálculo da estabilidade tecnogênica de verificação dos impactos, os indicativos e indicadores sociais que emolduram as paisagens, no decorrer do tempo, tornam-se imprescindíveis nas análises de planejamento para o ordenamento territorial.

A importância do diagnóstico está aliada ao sistema natural, cultural e social. É nessa complexidade tríade e trialética ${ }^{8}$ que se define uma paisagem, e não por meio de uma mera fotografia, apesar de saber que, até na fotografia, toda percepção e todo foco analítico depende do olhar e do ângulo de captação de quem registra o que vê.

Definir, diagnosticar, classificar, interpretar e representar paisagens não é tarefa fácil. E muito menos simples. Requer investigação e perícia e intercruzamento de dados, informações e conhecimentos complexos de disciplinas que estão ou não, na interface da Geografia.

A espacialização de paisagens requer além do diagnóstico e do inventário detalhado, uma equipe multidisciplinar, tendo em vista que o estudo é de natureza inter e transdisciplinar. A análise espacial, lida com o tratamento da informação, com banco de dados primários e secundários e registra métodos empíricos coletados em campo. É traduzida como um sistema de metodologias, banco de dados setorizados, planilhas eletrônicas e projetos conceituais de mapeamentos.

A paisagem, seja ela patrimônio natural ou cultural, interfere no planejamento e no ordenamento territorial, pois é possível prever os impactos provenientes de desastres naturais ou antrópicos e possibilitar o bem-estar humano. É possível contribuir para

\footnotetext{
8 O sentido dado aos vocábulos "tríade" e "trialético", neste contexto, refere-se à lógica analítica dos três sistemas: natural, cultural e social, constituintes da mesma unidade paisagística (totalidade sistêmica). No entanto, pode-se fazer uma analogia da tríade paisagística em relação à "tríade espacial" de referência lefebvriana: "espaço percebido (aquele da prática espacial), espaço concebido (relacionado às representações do espaço) e espaço vivido (referente aos espaços de representação)". Sobre a tríade espacial, leia La production de l'espace, de Henri Lefebvre (2000).
}

REVISTA GEONORTE, V.9, N.33, p.16-36, 2018.

DOI: 10.21170/geonorte.2018.V.9.N.33.16.36

(ISSN 2237 - 1419) 
AS NOÇÕES DE PAISAGEM: UMA ABORDAGEM MULTIDISCIPLINAR PARA O DIAGNÓSTICO AMBIENTAL E A GESTÃO TERRITORIAL

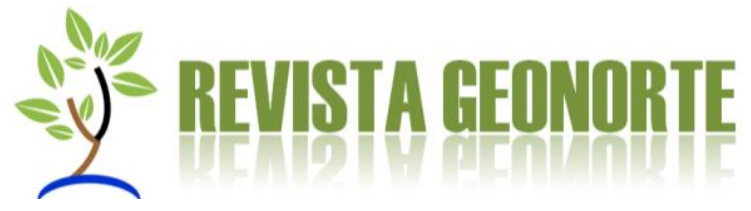

tornar os esforços de planejamento mais eficientes, no aprimoramento das metodologias utilizadas e desenvolver uma base de informações que dê conta da sistematização e divulgação de experiências de planejamento e dos resultados das pesquisas científicas sobre a paisagem, em todas as dimensões, já classificadas.

O diagnóstico tornará ainda mais relevante, não só por meio do levantamento de informações socioambientais (elementos físicos, biológicos e socioeconômicos) e por meio da produção de conhecimento, com levantamento de campo, mas também, no subsídio e orientação para as tomadas de decisão e processos de planejamento, gerenciamento e ordenamento territorial, no sentido de indicar estratégias e linhas de ação, nas desafiantes atuações de gestão ambiental humana, política e social, bem como na erradicação de problemas.

\section{AGRADECIMENTO}

Agradeço a CAPES - Coordenação de Aperfeiçoamento de Pessoal de Nível Superior -, pela concessão de Bolsa de Doutorado em Geografia, por mérito.

\section{REFERÊNCIAS}

AB'SÁBER, A. Os domínios de natureza no Brasil: potencialidades paisagísticas. $1^{\underline{a}}$ ed. São Paulo: Ateliê Editorial. 2003. ISBN 978-85-7480-596-2.

ADLER, M. J.; DOREN, C. V. Como ler livros: o guia clássico para a leitura inteligente. Tradução de Edward Horst Wolff e Pedro Sette Câmara. São Paulo: É Realizações Editora. (Coleção Educação Clássica).

ALAMI, S.; DESJEUX, D.; GARABUAU-MOUSSAOUI, I. Os métodos Qualitativos. Tradução de Luis Alberto S. Peretti. Rio de Janeiro: Petrópolis, Editora Vozes. 2010.

ALMEIDA, F. G. O ordenamento territorial e a geografia física no processo de gestão ambiental. In: SANTOS, Milton; BECKER, Bertha, K. et al. Território, territórios: ensaios sobre o ordenamento territorial. $3^{\text {a }}$ ed. Rio de Janeiro: Lamparina. 2011. Capítulo 15. p. 332-352. ISBN 978-85-98271-42-2.

BAILLY, A.; FERRAS, H. Éléments d'épistémologie de la géographie. 2ª ed. Paris: Armand Colin. 2006. ISBN 2-200-26670-7. CHRISTOFOLETTI, Antonio. Modelagem de sistemas ambientais. $1^{\text {a }}$ ed. São Paulo: Blucher. 1999. ISBN 978-85-212-0177-9.

CHRISTOFOLETTI, A. Modelagem de sistemas ambientais. 1a ed. São Paulo: Blucher. 1999. ISBN 978-85-212-0177-9.

CLAVAL, P. "A volta cultural” na geografia. Mercator, Fortaleza, v. 1, n. 1, jan. 2009. ISSN1984-2201.Availableat: <http://www.mercator.ufc.br/mercator/article/view/192>. Date accessed: 11 oct. 2018. doi: https://doi.org/10.4215/rm.v1i1.192. 
AS NOÇÕES DE PAISAGEM: UMA ABORDAGEM MULTIDISCIPLINAR PARA O DIAGNÓSTICO AMBIENTAL E A GESTÃO TERRITORIAL

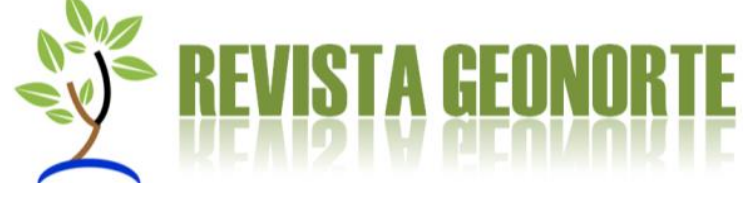

MATEO RODRIGUEZ, J. M. La concepcion sobre los paisajes vista desde la Geografia. La Habana, Cuba: Universidad de La Habana. Facultad de Geografia. "Año de la Alternativa Bolivariana para las Américas". Enero, 2005, p. 1-28.

MATEO RODRIGUEZ, J. M; SILVA, E. V.; CAVALCANTI, A. P. B. (Orgs.). Geoecologia das paisagens: uma visão geossistêmica da análise ambiental. $2^{\mathrm{a}}$ ed. Fortaleza: Edições UFC. 2007. ISBN 85-7282-148-1.

MAXIMIANO, L. A. Considerações sobre o conceito de paisagem. Raega - O Espaço Geográfico em Análise, [S.I.], v. 8, dez. 2004. ISSN 2177-2738. Disponível em: <https://revistas.ufpr.br/raega/article/view/3391>. Acesso em: 11 out. 2018. doi:http://dx.doi.org/10.5380/raega.v8i0.3391.

MERLEAU-PONTY, M. Fenomenologia da percepção. Tradução Carlos Alberto Ribeiro de Moura. 4a ed. São Paulo: Editora WMF Martins Fontes. 2011. ISBN 97885-7827-116-9.

MONTEIRO, C. A. F.. Geossistema: a história de uma procura, São Paulo. Contexto, 2000 ISBN 87-7244-144-1.

NUCCI, J. C.; FERREIRA, M. B. P.; VALASKI, S. Cobertura do solo e qualidade ambiental urbana como subsídios ao planejamento da Paisagem. In VI CONGRESSO IBEROAMERICANO DE ESTUDIOS TERRITORIALES Y AMBIENTALES, 2014, São Paulo. Estudios Territoriales. São Paulo: DG - FFLCH-USP, 2014. v. 1, p. 2886-2902.

PALLASMAA, J. Os olhos da pele: a arquitetura e os sentidos. Tradução Técnica: Alexandre Salvaterra. Porto Alegre: Bookman. 2011. ISBN 978-85-7780-777-2.

PORTO-GONÇALVES, C. W. A globalização da natureza e a natureza da globalização. 3ํㅗㄹ ed. Rio de Janeiro: Civilização Brasileira. 2012. ISBN 978-85-2000683-2

SALINAS, E. A. E. García, B. L. Miravet, R. Remond y E. Cruañas (2013) Delimitación, Clasificación y Cartografía de los Paisajes de la cuenca Ariguanabo, Cuba, mediante el uso de los SIG, Revista Geográfica del IPGH, No. 154 julio-diciembre, p. 9-30.

SALINAS, E. Referências bibliográficas indicadas e notas de aula e palestras. In: Seminário Temático I - Métodos para el diagnostico del paisaje en el ordenamiento y la planificación territorial Programa de Pós-Graduação em Geografia da Universidade Federal do Paraná, Brasil. Origem: Universidad de la Habana. Cuba. 2016.

SANTOS, R. F. Planejamento ambiental: teoria e prática. São Paulo: Oficina de Textos. 2004. ISBN 978-85-86238-62-8. 
AS NOÇÕES DE PAISAGEM: UMA ABORDAGEM MULTIDISCIPLINAR PARA O DIAGNÓSTICO AMBIENTAL E A GESTÃO TERRITORIAL

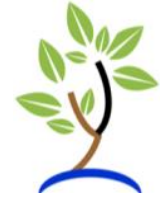

SANTOS, M. A natureza do espaço: técnica e tempo. Razão e emoção. 4⿳亠丷a ed. São Paulo: EDUSP. 2012. ISBN 978-85-314-0713-0.

SCHIER, R. A. Trajetórias do conceito de paisagem na geografia. Raega - O Espaço Geográfico em Análise, [S.I.], v. 7, dez. 2003. ISSN 2177-2738. Disponível em: <https://revistas.ufpr.br/raega/article/view/3353/2689>. Acesso em: 11 out. 2018. doi:http://dx.doi.org/10.5380/raega.v7i0.3353.

SEGUINOT, J. Globalization of the Landscape or Puerto Rico. In Globalization in America: a geographical approach: Instituto de estudios del Caribe, San Juan. P. R. 1996, p. 79-92. Tuan, Yi-Fu. Topophilia: a study of environmental perception, attitudes, and values. New Jersey: Prentice Hall - Englewood Cliffs, 1974 ISBN 10.0139252304.

VITTE, A. C. O desenvolvimento do conceito de paisagem e a sua inserção na geografia física (the development of landscape concept and its interaction with physical geography). Mercator, Fortaleza, v. 6, n. 11, p. p. 71 a 78, nov. 2008. ISSN 1984-2201. Available at: <http://www.mercator.ufc.br/mercator/article/view/58>. Date accessed: 11 oct. 2018. 